\title{
The Differential Effects of Competitive Funding on the Production Frontier and the Efficiency of Universities
}

\author{
Thomas Bollia ${ }^{\mathrm{a}, 1, *}$, Maria Olivares ${ }^{\mathrm{b}}$, Andrea Bonaccorsi ${ }^{\mathrm{c}}$, Cinzia Daraio ${ }^{\mathrm{d}}$, Adela \\ Garcia Aracile ${ }^{\mathrm{e}}$ Benedetto Leporif \\ ${ }^{a}$ ETH Zurich, KOF Swiss Economic Institute, Leonhardstrasse 21, CH-8092 Zurich, \\ Switzerland \\ ${ }^{b}$ University of Zurich, Department of Business Administration, Plattenstrasse 14, CH-8032 \\ Zurich, Switzerland \\ ${ }^{c}$ University of Pisa, Dipartimento di Ingegneria dell'Energia, dei Sistemi, del Territorio e delle \\ Costruzioni, Pisa, Italy \\ ${ }^{d}$ Sapienza University of Rome, Department of Computer, Control and Management \\ Engineering, via Ariosto, 25 I-00185, Rome, Italy. \\ ${ }^{e}$ Universitat Politècnica de València, ingenio CSIC-UPV, s/n 46022, Valencia, Spain. \\ ${ }^{f}$ Università della Svizzera italiana, via Lambertenghi 10a, 6904 Lugano, Switzerland.
}

\begin{abstract}
European governments increasingly employ competitive university funding to improve performance in higher education. The framework that is developed in this paper suggests a donor-specific trade-off between fostering best performing universities and increasing university efficiency when introducing competitive funding in the university sector. We test this assertion based on a university-level panel dataset across eight European countries from 1994-2006. Estimating a simultaneous two-stage Stochastic Frontier Approach, we find that international public funds decrease the productivity of the best performing universities, which suggests a non-negligible effect because of the administrative burden induced by competitive funding. However, the competition for international public funds also disciplines universities as evidenced by a positive impact on efficiency. Conversely, tuition fees enhance the productivity of the best performing universities but increase the spread of universities with lower productivity, which suggests a strong sorting effect.
\end{abstract}

Keywords: University, Third-Party Funding, Stochastic Frontier Analysis, Production Frontier, Efficiency

\footnotetext{
${ }^{*}$ Corresponding Author

Email addresses: bolli@kof.ethz.ch (Thomas Bolli), maria.olivares@business.uzh.ch (Maria Olivares), a.bonaccorsi@gmail.com (Andrea Bonaccorsi), daraio@dis.uniroma1.it (Cinzia Daraio), agarcia@ingenio.upv.es (Adela Garcia Aracil), blepori@usi.ch (Benedetto
} Lepori) 
JEL-Classification: I22, I23, I28

***This paper used the dataset produced by the Aquameth project, a project funded by the European Commission through the PRIME Network of Excellence. We are grateful for the comments of Peter Egger, Mehdi Farsi, William Greene, Marius Ley and Andrea Schenker-Wicki. We would also like to thank the participants of the KOF Brown Bag Seminar, the First Valencian Workshop on Efficiency and Productivity, the BYOSS Seminar, the First Lisbon Research Workshop on Economics and Econometrics of Education, the ISU Lunch seminar and two anonymous referees for their helpful comments and discussions on previous versions of this paper. Thomas Bolli further thanks the Swiss National Science Foundation for funding. The views expressed herein are the views of the authors only.

\section{Introduction}

Since the late 1990s, the European higher education system has faced an essential transformation process that reflects the rising relevance of the knowledge economy. To stimulate the competitiveness and efficiency of the European higher education system mandated by the Lisbon Agenda of 2000, the authorities of national governments and the European Union introduced market- or quasi-market-like mechanisms to the system [81, 82]. Accordingly, the pan-European governments increasingly employ competitive funding schemes to improve the performance of universities [see, e.g., 34].

The literature, however, provides little insight regarding the theoretical foundation that underlies the impact of competitive funding sources on the production process of universities. Furthermore, the scant empirical evidence remains ambiguous [see, e.g., 83]. Although [25] find a positive impact of third-party funding on efficiency, the results of [73] indicate an inversed u-shaped effect. [22] identify a positive effect of public third-party funding on efficiency [20] report an inverse u-shaped relation between private funding and efficiency, whereas [22] find no impact. [1] show that competition for overseas students has improved university efficiency in Australia but not in New Zealand. The findings of [2] imply that competition for students increases the efficiency of Italian universities. In addition to providing ambiguous evidence, these papers focus on the impact of thirdparty funding on efficiency but remain silent regarding the effect on the production frontier. Furthermore, these studies fail to address the problem of endogeneity.

To our knowledge, only three papers address the problem of endogeneity. Analysing an Australian higher education reform that introduces competitive funding, [21] find a positive impact on research productivity. Using an instrumental variable approach, [7] show a positive causal impact of competitive public funding on university productivity. Similarly, the findings of [17] suggest that competitive public funding increases basic research productivity, whereas private funding enhances the productivity of applied research. Because these papers focus on aggregate productivity, they allow no inference regarding the differential impact of third-party funding on the production frontier and efficiency. However, this information is important for policy makers because it suggests different implications for organising a higher education system. These implications 
depend on the objectives of governmental authorities, that is, fostering the best performing universities on the production frontier or catching up universities to the production frontier.

We extend the existing literature in three main directions. First, based on the principal-agent theory where the donor of third-party funds is the principal and universities or individual researchers are the agents [see, e.g., 56], we develop a simple theoretical framework. This framework illustrates the channels through which three competitive funding sources - budget shares financed by international public funds, private funds and tuition fees as the main financial resources along with the university core budget [19] - affect the production frontier and efficiency of universities. ${ }^{1}$ We call these effects administrative effect, competition effect and sorting effect. Second, we test our hypotheses empirically by using a simultaneous two-stage Stochastic Frontier Approach, a method that allows us to disentangle the effects of competitive funding on best practice production and the spread of university (in)efficiency. Third, exploiting a university-level panel dataset across 8 European countries between 1994 and 2006 allows us to address the problem of endogeneity due to unobserved heterogeneity and reverse causality.

Our findings suggest that introducing competition in the university sector entails a donor-specific trade-off between enhancing the production frontier and fostering efficiency that politicians should consider. In particular, we find that international public funds decrease the production frontier, which suggests a substantial administration effect, that is, a non-negligible administrative burden to apply for funding and report research results. However, we further find evidence of a competition effect that disciplines universities as evidenced by a positive impact of international public funds on university efficiency. This result shows that the concrete implementation of the competitive funding scheme matters substantially for potential productivity gains. The results for private funds are ambiguous. We further find that tuition fees enhance the production frontier but decrease efficiency, suggesting a strong sorting effect that arises because researchers and students sort themselves according to productivity. This result suggests that the concrete implementation scheme of tuition fees should account for the potential effects of tuition fees on equity in higher education.

The paper is structured as follows. Section 2 presents our simple theoretical framework. Section 3 explains the methodology and the estimation approach we applied, and Section 4 provides information on the data that are used for our analysis. Section 5 presents and discusses our estimation results and is followed by a conclusion in Section 6 .

\footnotetext{
${ }^{1}$ Following the concept of frontier analysis, the production frontier defines 'best practice' and is built by the best performing universities that are defined as being technically efficient. Thus, inefficiency is determined by the deviation from this production frontier; all universities that do not operate at this production frontier are defined as being technically inefficient.
} 


\section{Theoretical framework}

This section introduces the conceptual background of our analysis. Further, we develop a simple theoretical framework by discussing three different channels through which competitive funding may influence both the production frontier and the efficiency of universities. The concept of production frontier corresponds to estimating the outer boundary of university production, that is, the production frontier is defined by the best performing universities concerning both the use of technology and the application of management techniques [e.g., 42]. All universities on the frontier are identified as technically efficient, whereas all universities below this frontier are identified as technically inefficient; (in)efficiency is measured as the distance relative to the production frontier.

In the context of the principal-agent theory [see, e.g., 10, 48, 74], public funding agencies, private companies and students represent principals that delegate the activities of research and education to the more specialised agent. Because the empirical framework relies on university level data, our discussion often denotes universities as the principal. However, in reality, the principal-agent relationship is complicated even further because the agent is often not the aggregate university but the individual researcher. Due to the asymmetric information that favours researchers and universities, this principal-agent relationship is characterised by moral hazard and hidden action if conflicting interests between the donor and the researcher or the university exist [64, 11, 82]. This situation may occur, e.g., because the researchers' primary interest may be to secure their role and position in the scientific system rather than to satisfy the objectives of the donor [see, e.g., 82]. Therefore, the donor establishes control mechanisms to verify the academics' effort by using, e.g., performance monitoring in the reporting on the projects and financial statements as well as peer review procedures and audits [e.g., 56, 82].

Based on this principal-agent framework, we distinguish three channels through which third-party funding may influence the production process of universities and researchers. In particular, we differentiate between the administration effect, the competition effect and the sorting effect. The following paragraphs discuss each effect in more detail. Table 1 further summarises our hypotheses regarding the effects we expect for international public funds, private funds and tuition fees.

The first and most apparent channel reflects the administrative effort that third-party funding induces, which we call the administration effect. The acquisition of external funds requires academics to invest time and money in reporting on the research progress and the use of funds, which occurs at the expense of research and teaching activities $[82] .^{2}[58]$ supports this view by showing that funding source choices depend on the effort required by grant application and report procedures. Furthermore, [17] suggest that the administration effect may occur because the donor directly controls the behaviour of universities. Due to the incomplete information available to the donor, these restrictions

\footnotetext{
${ }^{2}$ Other costs born by the donor, e.g., the costs of peer review procedures and audits, must be considered when evaluating the funding system as a whole. However, a full cost-benefit analysis is beyond the scope of this paper.
} 
may result in the inefficient behaviour of universities that is suggested by the empirical evidence of [57] and [63].

In case of funding agencies and private companies, we assume that the administration effect results in a decrease of the production frontier because of the costs of adhering to the control mechanisms. As most researchers and universities apply for third-party funding - regardless of the extent of third-party acquisition - these costs reduce the productivity of all universities equally; therefore, only the production frontier, not efficiency, is affected. Similarly, tuition fees may induce researchers and universities to increase efforts aiming to improve their reputation with parents and prospective students, e.g., by visiting high schools, organising open days and marketing their universities. However, the administration effect may be lower concerning tuition fees for two reasons. First, these efforts are largely conducted at the university level as opposed to the level of individual researchers, which may create substantial economies of scale. Second, a larger share of monitoring costs may be borne by parents and prospective students. Therefore, the administration effect that is induced by tuition fees may be lower than for competitive research funding.

The second channel, which we call the competition effect, arises because of the increasing competition for third-party funding. This competition limits the ability of researchers to pursue their own goals at the expense of the donor and therefore leads to a more productive use of the funds [see, e.g., 65, 66, 53, 11, 8]. Given several higher education reforms across Europe, the competition for research funding has created a 'market-like' environment [81]. Universities and researchers are induced to focus on whether their teaching and research is compelling and productive, which motivates them to make strategic choices to improve efficiency. [8] However, the relation between growing competition and university productivity and efficiency is supported by a small body of empirical literature. [21] shows that the introduction of competitive funding based on output counts has increased the share of Australia's ISI publications despite declining resources. [25] find a positive correlation between the share of scientific research grants and efficiency, but a negative effect from the funds for contract research in Dutch universities. Additionally, [1] find that competition for overseas students increases university efficiency in Australian universities. [2] analyses the relation between the competition for students and university production in teaching in Italy and finds a positive effect of competition on university performance. Assuming further that study tuition fees induce students to choose their preferred university by 'voting with their feet', the competition for students may avoid an inefficient allocation of resources [53].

We therefore assume that the competition for third-party funding may have a positive impact on the production frontier of best practice, particularly on the spread of university efficiency. This assumption is made because competition disciplines institutions to operate more efficiently and therefore prevents moral hazard. In particular, the universities that operate below the production frontier will increase their efficiency and catch up to the best performing universities. We assume that the universities that already operate on the production frontier face competition for financial resources against other higher education institutions on the national and international markets. There- 
fore, we hypothesise that competitive funding has stronger effects on the universities below the frontier than on the universities that are on the production frontier. Thus, we suggest that the variation in efficiency between the best performing and the worst performing universities will decline.

The third channel, which we call the sorting effect, may occur because the competition for third-party funding intensifies the sorting of researchers and students into universities according to productivity. For example, researchers choose universities based on their reputation and research environment, and universities hire researchers with strong research tracks [see, e.g., 6, 26]. Likewise, students increasingly base their enrolment decisions on ranking criteria, and universities evaluate prospective students, e.g., via numerus clausus, test scores, entry examinations, and interviews. The empirical evidence supports the existence of the sorting effect for both academics [see, e.g., 30] and students [see, e.g., 29, 23, 46, 39, 16, 59].

Therefore, we assume that the sorting effect increases the production frontier determined by the best performing universities but decreases the productivity of the universities that are below the frontier. In particular, the best performing universities can attract and, thus, select high-ability researchers and students because they provide highquality teaching and research conditions. Mirroring this sorting effect, the universities that operate below this production frontier can select only from the pool of the remaining personnel and students. Because of the selection of high potentials that favour the best performing universities, the sorting effect induces an increasing spread between the universities that operate efficiently and the universities that operate inefficiently. It should be noted though that substantial heterogeneity of departmental quality within a university exists.

Table 1: Expected effects of competitive funding on the production frontier of best-practice and university efficiency

\begin{tabular}{l|cccc}
\hline & Adm & Comp & Sort & Total \\
\hline Best-practice frontier & - & + & + & $?$ \\
Efficiency & 0 & + & - & $?$ \\
\hline
\end{tabular}

Table 1 summarises the expected aggregate impact and the expected impact of each channel on the production frontier of best practice and university efficiency concerning international public funds, private funds and tuition fees. To facilitate interpretation, the table and the discussion thereafter refers to the spread of inefficiency as efficiency, that is, it reverses the interpretation vis-à-vis the empirical setting. The administration effect has a negative impact on the production frontier, which may be more pronounced for competitive research funding than for tuition fees. This difference may be because many of the efforts to increase reputation occur at the university level and because a larger share of the monitoring costs are covered by the principals, i.e., the parents and prospective students. For all three competitive funding sources, we also assume that 
the competition effect improves productivity by disciplining universities and researchers and, therefore, shifts the production frontier outwards. As the competition effect is assumed to affect inefficient universities more than efficient universities, it further increases university efficiency. Moreover, the sorting effect is assumed to have a positive effect on the production frontier but a negative effect on efficiency because it increases the spread between the best and worst performing universities. Given these assumptions, we remain agnostic regarding the expected aggregate impact of third-party funding on both the production frontier and efficiency.

Nevertheless, our simple framework enables an interpretation of the empirical findings in terms of the dominance of the administration, the competition and the sorting effects. A negative impact on the production frontier suggests that the administration effect dominates the competition and sorting effects, whereas a positive effect on the production frontier suggests that the competition or the sorting effect dominates. Furthermore, a positive impact of funding shares on efficiency reveals that the competition effect outweighs the sorting effect, whereas a negative impact suggests that the sorting effect prevails. Combining these arguments, we expect a positive impact of competitive funding on the production frontier to originate from the sorting effect if the impact on efficiency is negative. However, a positive impact on efficiency may still suggest that the sorting effect causes the outward shift in the production frontier, as we assume a relatively small impact of the competition effect on the production frontier.

However, this interpretation assumes that both universities on and below the production frontier compete for external funding to the same extent. If, e.g., low productivity researchers and universities do not apply for funding because their success probability is too low, they forego productivity gains from the competition effect but also save the burden of the administration effect. In this case, the effect of external funding on university efficiency is ambiguous. If the reputation of high productivity universities insulates them from competing with other universities or complying fully with the administrative requirements of the donors, the effect of external funding on the best-practice frontier is also ambiguous. Therefore, the heterogeneity of the effect of external funding across universities provides an observationally equivalent explanation. Nevertheless, we discuss our findings concerning the above hypotheses and assume that the relevance of heterogeneity in the effects is smaller than the direct effects of the administration, competition and sorting effects.

\section{Methodology}

To analyse the effect of competitive funding on both the production frontier of best practice and university efficiency, this study employs the multi-input, multi-output distance function approach that is proposed by [76, 77]. The distance function approach allows us to identify 'best practice' production by modelling the distance from the production frontier as a function of the vector of inputs, $x$, the level of outputs, $y$, and the vector of university characteristics, $z$. This concept of frontier measures is different 
from productivity estimations based on regression analysis, which estimates the average productivity. ${ }^{3}$

A distance function can be specified as either input-oriented or output-oriented, depending on the assumption regarding whether inputs or outputs are exogenously determined. Following [1], we utilise an output distance function assuming that universities maximise the output for a given amount of inputs. This assumption appears reasonable because the inputs of universities are mostly determined by politicians. We define the output distance function on the output set, $P(x, z)$, as:

$$
D^{O}(x, y, z)=\min \{\theta:(y / \theta) \in P(x, z)\}
$$

where $P(x, z)$ represents the set of all non-negative input vectors, $x=\left(x_{1}, \ldots, x_{K}\right) \in R_{+}^{K}$, that can produce the non-negative output vector, $y=\left(y_{1}, \ldots, y_{M}\right) \in$ $R_{+}^{M}$, given the exogenous variables, $z=\left(z_{1}, \ldots, z_{S}\right) \in R_{+}^{S}$, that reflect university characteristics. $D^{O}(x, y, z)$ denotes the distance from the university's output set, $P(x, z)$, to the production frontier. [41] showed that the distance function, $D^{O}(x, y, z)$, is linearly homogeneous of degree 1 in outputs and satisfies the economic regularity conditions of monotonicity and convexity, that is, the function is non-decreasing and convex in outputs, $y$, and non-increasing in inputs, $x$. $\theta$ is the scalar distance by which the output vector can be deflated [see, e.g., 28], and it can be interpreted as the level of inefficiency. According to the [38] definition ${ }^{4}$, if $y \in P(x, z)$, then $D^{O}(x, y, z)=\theta \leq 1$, which means that the distance function will take a value that is less than or equal to 1 if the output vector, $y$, is an element of the feasible production set, $P(x, z)$. If the output vector is located on the outer boundary of the output set, which is the production frontier, universities are identified as being fully efficient, whereas values less than 1 correspond to inefficient output vectors that lie below the production frontier.

The empirical estimation follows the parametric Stochastic Frontier Analysis proposed by $[9,62]$. Because this methodology controls for statistical noise, it allows us to easily integrate environmental variables, such as funding shares, and it enables us to exploit and account for the panel data structure. ${ }^{5}$ Due to the parametric nature of stochastic distance functions, it is necessary to determine the relation between inputs, outputs and observable, university-specific factors by specifying the functional form for the underlying production technology, $P\left(x_{i t}, z_{i t}\right)$. We apply the translog specification because it represents a relatively flexible functional form, that is, it does not impose any restrictions on the elasticities of production, economies of scale and the elasticity of substitution as a Cobb-Douglas function does. Using a translog production func-

\footnotetext{
${ }^{3}$ See [18] for further discussion on this issue.

${ }^{4}$ Following the [38] definition, technical efficiency represents the reciprocal of the value of the (Shepard) distance function.

${ }^{5}$ For the early developments to introduce noise and environmental variables in the nonparametric Data Envelopment Analysis methodology, see [14, 71, 75]. For more recent contributions and applications, see, e.g., [32, 33, 67, 12, 13]. [61] and [52] provide a comparison of parametric and non-parametric efficiency measures of universities.
} 
tion specification provides a second-order approximation of the true production function because cross-terms are included in the log-linear form [27].

The stochastic frontier estimation of the translog output distance function ${ }^{6}$ for $K(k=$ $1, \ldots, K)$ inputs $x_{i t}, M(m=1, \ldots, M)$ outputs $y_{i t}$ and $(s=1, \ldots, S)$ observable, universityspecific factors $z_{\text {sit }}$ can be written as follows: ${ }^{7}$

$$
\begin{aligned}
\ln y_{M_{i t}}= & \alpha_{0}+\alpha_{t}+\sum_{m=1}^{M-1} \alpha_{m} \ln y_{m i t}^{*}+\frac{1}{2} \sum_{m=1}^{M-1} \sum_{n=1}^{M-1} \alpha_{m n} \ln y_{m i t}^{*} * \ln y_{n i t}^{*} \\
& +\sum_{k=1}^{K} \beta_{k} \ln x_{k i t}+\frac{1}{2} \sum_{k=1}^{K} \sum_{l=1}^{K} \beta_{k l} \ln x_{k i t} * \ln x_{l i t} \\
& +\sum_{k=1}^{K} \sum_{m=1}^{M-1} \eta_{k m} \ln x_{k i t} * \ln y_{m i t}^{*}+\sum_{s=1}^{S} \gamma_{s} z_{s i t}+\nu_{i t}-u_{i t}
\end{aligned}
$$

where the dimensions $i=1, \ldots, I$ and $t=1, \ldots, T$ denote university and time, respectively. $\alpha, \beta, \eta$, and $\gamma$ are unknown parameter vectors to be estimated; $\alpha_{0}$ and $\alpha_{t}$ capture the constant and time dummies, respectively. Inputs, outputs and observable university characteristics are normalised by the sample median. The composed error term, $\epsilon_{i t}$, consists of $\nu_{i t}$ and $u_{i t} . \nu_{i t}$, accounts for statistical noise and follows a normal distribution, $\left(\nu_{i t} \sim\right.$ iid $\left.N\left[0, \sigma_{\nu}^{2}\right]\right)$. The non-negative random error term component, $u_{i t}$, which is independently distributed from the $\nu_{i t}$ component, captures technical inefficiency. We assume that this component follows a half-normal distribution, $\left(u_{i t} \sim i i d N^{+}\left[0, \sigma_{u}^{2}\right]\right)$.

The observable, university-specific factors, $z_{s i t}$, refer to the budget shares that are financed by international public funds, private funds and tuition fees. We include these factors in a quadratic form because coefficient estimates are more stable across models, models converge more smoothly and the results indicate some non-linearities in the effect of budget shares. ${ }^{8}$ Including $z_{\text {sit }}$ in the production function estimation directly suggests that these variables affect the production frontier of best performing universities. However, given the theoretical considerations presented in Section 2, we remain agnostic concerning whether third-party funding has an impact on the production frontier, the

\footnotetext{
${ }^{6}$ Assuming an input distance function instead yields qualitatively similar results. We discuss exceptions in the results section. These estimates can be obtained from the authors upon request.

${ }^{7}$ The estimation imposes the necessary symmetry restrictions, that is, $\alpha_{m n}=\alpha_{n m}$ for $m, n=1,2, \ldots, M$ and $\beta_{k l}=\beta_{l k}$ for $k, l=1,2, \ldots, K$ and linear homogeneity of degree one, that is, $\sum_{m=1}^{M} \alpha m=1, \sum_{n=1}^{M} \alpha_{m n}=0$ for $m=1,2, \ldots, M$ and $\sum_{m=1}^{M} \beta_{m k}=0$ for $k, l=1,2, \ldots, K$ by using an arbitrary output $y_{M}$ as the dependent variable and normalising all other outputs by $y_{M}$ [see, e.g., 27, 42]. As it is more consistent with the expected signs of parameters in conventional production frontiers, we further follow studies that use $\ln \left(y_{M_{i t}}\right)$ as the dependent variable instead of $-\ln \left(y_{M_{i t}}\right)$ [see, e.g., $\left.70,69,1\right]$.

${ }^{8}$ Modelling budget shares linearly yields qualitatively the same results. These results are available from the authors upon request.
} 
spread of university inefficiency, or both. To model the differential impact of the funding sources on both the production frontier and efficiency, we follow [24], who incorporate heterogeneity in the variance of $u_{i t}$, which accounts for heteroscedasticity in the inefficiency term as proposed by [72] and [78]. ${ }^{9}$ Modelling the variance of the inefficiency term as a function of the third-party funding shares, $\left(u_{i t} \sim i i d N^{+}\left[0, \sigma_{u}\left(z_{s i t}\right)^{2}\right]\right)$, the inefficiency equation, which is jointly estimated with the production function by using the maximum likelihood technique, can be written as:

$$
\sigma_{u_{i t}}^{2}=\psi_{0}+\delta_{s} z_{s i t}+\omega_{i t}
$$

where $\psi_{0}$ and $\delta$ denote parameter vectors to be estimated, and $\omega_{i t}$ refers to a normally distributed error term, $\left(\omega_{i t} \sim\right.$ iid $\left.N\left[0, \sigma_{\omega}^{2}\right]\right)$. As the inefficiency term, $\sigma_{u}^{2}$, follows a halfnormal distribution, a decrease in the variance leads to an increase in average efficiency [see, e.g., 40]. A positive coefficient of $\delta$ indicates that the spread regarding technical inefficiency between the best and the worst performing universities increases. Therefore, efficiency decreases.

The above methodology captures our attempt to disentangle the correlations among third-party funding shares, the production frontier and the spread of efficiency in university production. However, many reasons exist why the observed correlations may not reflect causality [see, e.g., 7]. The first reason is reverse causality, that is, the possibility that third-party funding goes to productive universities instead of inducing productive behaviour. The second problem is unobserved heterogeneity, such as student and staff quality, which may cause identification problems that may be related to the ability of universities to attract competitive funding. This possibility is particularly true because we use a university-level estimation, which ignores heterogeneity in universities, e.g., in terms of department quality and scientific subject specialisation. Third, the data may involve measurement errors that are correlated with the error term, which biases our estimation results.

Exploiting the panel nature of our dataset allows us to employ three alternative strategies to address these problems of endogeneity. In this way, we restrict ourselves to use only particular parts of the variance that are less susceptible to endogeneity. However, the high data demand that is required to identify the differential effects of funding shares on best-practice, the spread of university efficiency, and the relatively low amount of variance in the funding shares over time limits our attempt to use variation that is beyond any doubt of endogeneity. Nevertheless, this analysis allows us to provide

\footnotetext{
${ }^{9}$ The preliminary analysis of our study suggests assuming an exponential distribution fail to converge if we include budget shares in both the production function and inefficiency equation. However, including budget shares in either equation individually yields qualitatively the same results as reported in the paper. These results are available from the authors upon request. Table A3 in the Appendix shows that our results are robust to include budget shares in either the production function or the inefficiency equation only, which suggests that this validation approach is feasible.
} 
initial evidence regarding a causal interpretation of our findings. It remains a task for future research to confirm these results.

Our first model specification includes country-specific intercepts in the production function estimation, which addresses the problem of unobserved heterogeneity across countries. Therefore, we employ a model in the spirit of the true fixed effect stochastic frontier model as proposed by [44, 45], but convergence problems force us to define the fixed effects on the level of countries as opposed to the university level. ${ }^{10}$ However, including fixed effects does not account for reverse causality. To address the problem that current productivity affects funding acquisition, our second model specification lags funding share variables by two years in addition to the country-fixed effects. The lag length of two years is chosen to ensure that current productivity has no effect on funding acquisition. ${ }^{11}$

Applying country-fixed effects and lagged values solves endogeneity regarding reverse causality and unobserved heterogeneity at the country level. However, unobserved heterogeneity in a country and in universities, e.g., because of differences in departmental quality or scientific field mix, still remains a potential source of endogeneity. To test whether this drives our results, we thirdly report a model specification that uses the country averages of funding shares. Combining these three approaches, namely, including country-specific intercepts, lagging budget share variables and using country averages, places substantial demands on the available variation. Therefore, we report different combinations of these approaches to provide support for the hypothesis that the observed correlations represent a causal effect.

\section{Data}

The data that are used in this study originate from the Aquameth database, a temporary European project that has established an extensive dataset containing comparable university-level statistics across many European countries. Detailed information on the terminated Aquameth project, its database and analyses of cross-country comparisons can be found in [19], [79] and [31]. ${ }^{12}$ Because of the issue of data availability, we use the unbalanced data of Finland, Italy, the Netherlands, Norway, Portugal, Spain, Switzerland and the UK between 1994 and $2003 .^{13}$

\footnotetext{
${ }^{10}$ The models that include additional dummy variables for each country in the inefficiency equation yield qualitatively the same results. These results can be obtained from the authors upon request.

${ }^{11}$ Using lags of one or three years yields qualitatively the same results. These results are available from the authors upon request.

${ }^{12}$ For an overview regarding the project, see also http://www.prime-noe.org/aquameth. html.

${ }^{13}$ Despite every effort, the variable definitions remain somewhat heterogeneous across countries. The examples include personnel, which is not measured in full-time equivalent for all countries, differences in the inclusion of Ph.D. students as staff and incoherence regarding how international public funds are measured. Therefore, our data include a measurement error. We
} 
The literature on university efficiency has grown rapidly, which is evidenced by the literature reviews of [86] and [50], including many recent cross-country studies [see, e.g., $3,5,4,54,68,85]$. We include three inputs in our output distance function, namely, professors and assistant professors, other researchers, and technical and administrative staff. The category of professors includes persons who are employed in stable, mostly full-time academic positions, whereas the category of other researchers reports all persons whose specific assignments are to conduct research as their principal activity (e.g., postdoctorates, Ph.D. candidates, and senior researchers). The technical and administrative staff include all non-academic personnel.

To capture the teaching output of universities, we use the information on enrolled students that comprise the university's first degree and bachelor's and master's degree students. ${ }^{14}$ To measure the research output, we include the total number of ISI publications. Although some of the literature uses external research funding to approximate research output [see, e.g., 47, 80, 51, 49], there is an ongoing debate on whether this is warranted because external research funding can be considered intermediate outputs [see, e.g., 5, 43]. In the present context, we use the number of ISI publications mainly to avoid endogeneity and multicollinearity between our measures of external funding shares and research output. However, this approach has the drawback that data availability prevents us from distinguishing field-specific publication behaviour and adjusting for the quality of publications.

Moreover, the data include detailed information on the financial resources of each university, which allows us to construct the shares of the total budget ${ }^{15}$ that are financed by revenues from international public funds, private funds and tuition fees. ${ }^{16}$ The revenues from international public funds include resources that were granted for specific research projects or teaching programmes from government and non-government agen-

address the potentially resulting endogeneity problems by introducing country dummies that rely on in-country variation to identify the coefficients. In addition, we provide robustness checks concerning whether dropping individual countries from the sample affects our results. These approaches qualitatively yield the same results, which suggests that the measurement error is random and is therefore captured by the error term rather than creating a problem of endogeneity.

${ }^{14}$ Because of the non-coherent treatment of Ph.D. students in the personnel data, we do not use them as a further output variable to avoid bias from double counting as input and output. We also regret not being able to incorporate quality indicators of teaching activities in universities, because no respective data were available [see, e.g., 60].

${ }^{15}$ Because of accounting and budgeting issues, the investments for buildings, laboratories, specialised equipment and revenues from the medical services of university hospitals are not included in the total budget figure.

${ }^{16}$ Unfortunately, the data used for analysis do not allow us to differentiate between general governmental appropriation and other financial resources that are granted by national public agencies, such as national resource councils. 
cies outside the country where the university operates. ${ }^{17}$ The revenues from private funds contain all grants and donations that are funded for research, consultancy and contract teaching by the business sector, non-profit organisation, foundations and other private entities. The revenues from tuition fees comprise all funds that students are charged for educational purposes, excluding charges for rooms, board and other services that are provided to students. The level of tuition fees for undergraduate students is highly regulated, although universities enjoy somewhat more freedom to set tuition fees at the graduate and postgraduate levels and for non-European students. Importantly, with the exception of the UK, tuition fees in most European countries represent a financial contribution and do not cover the total study costs, and in Norway and Finland, undergraduate education is tuition-free. ${ }^{18}$

Table 2 provides the overall summary of the descriptive statistics of the variables that were used for our analysis. Inputs, outputs and budget shares cover a wide range of values. At the sample average, a university produces 774 publications and enrols nearly 18,000 students. Most of the employed personnel refers to technical and administrative staff with a mean value of 904 employees. The average university employs approximately 650 professors and assistant professors in addition to 771 other researchers. The detailed information on the country-specific summary statistics is reported in Table A1 in the online appendix. ${ }^{19}$ Although in Italy and Spain the average number of enrolled students exceeds more than 30,000, this number amounts to less than 10,000 students in Finland and Switzerland. Compared with the relatively small student body in the Netherlands and Switzerland, these countries employ a relatively high number of academic and nonacademic personnel. Especially the number of researchers is comparably high and indicates that the universities in both countries seem to be more research-oriented, which is also reflected by the higher mean values of publications.

Moreover, the mean value of the budget shares that are financed by international public funds and private funds cover merely $2.3 \%$ and $5 \%$, respectively, whereas the budget shares of tuition fees amount to nearly $19 \%$ of the university budget. The countries' summary statistics that are reported in Table A1 in the online appendix also reveal substantial differences across countries. The highest mean value of the share of international public funds is equal to $6.6 \%$ in Portugal, whereas the lowest mean value of $1.5 \%$ relates to Switzerland. The average shares of the revenues from private funds is slightly higher, with the highest mean values for Portugal (22.8\%) and Finland (20.4\%) and the lowest in Norway $(2.04 \%)$ and Spain (1.2\%). Furthermore, in contrast to the Northern and Central European countries that have a low share of tuition fees, the tertiary sys-

\footnotetext{
${ }^{17}$ Probably most of the international public funds in our sample are granted by the Framework Programmes for Research of the European Commission.

${ }^{18}$ Because Norway and Finland have no tuition fees, there is no variation in tuition fees over time. Therefore, including country-fixed effects implies that the identification is based on the remaining sample only.

${ }^{19}$ We caution the reader to remember the heterogeneity of data collection when interpreting these numbers.
} 
Table 2: Overall summary statistics for the variables of the output distance function ${ }^{a, b, c}$

\begin{tabular}{|c|c|c|c|c|c|}
\hline Variable description & Variable & Mean & Std. Dev. & Min & Max \\
\hline Publications & $Y_{\text {publ }}$ & 774 & 1043 & 1 & 6964 \\
\hline Enrolled students & $Y_{\text {stud }}$ & 17935 & 20499 & 0 & 176154 \\
\hline Professors and assistant professors & $X_{\text {prof }}$ & 648 & 817 & 0 & 6080 \\
\hline Other research staff & $X_{\text {res }}$ & 771 & 850 & 0 & 6295 \\
\hline Technical and administrative Staff & $X_{a d m}$ & 904 & 727 & 38 & 6677 \\
\hline Budget share of tuition fees & $b s h a_{t u i t}$ & 0.187 & 0.110 & 0 & 0.704 \\
\hline Budget share of international public funds & $b s h a_{\text {pubint }}$ & 0.023 & 0.030 & 0.000 & 0.550 \\
\hline Budget share of private funds & $b s h a_{\text {priv }}$ & 0.047 & 0.064 & 0.000 & 0.402 \\
\hline $\begin{array}{l}\text { Yearly country average of budget share of } \\
\text { tuition fees }\end{array}$ & $b s h a_{c_{t u i t}}$ & 0.187 & 0.083 & 0.000 & 0.266 \\
\hline $\begin{array}{l}\text { Yearly country average of budget share of } \\
\text { international public funds }\end{array}$ & $b s h a_{c_{p u b i n t}}$ & 0.022 & 0.011 & 0.002 & 0.080 \\
\hline $\begin{array}{l}\text { Yearly country average of budget share of } \\
\text { private funds }\end{array}$ & $b s h a_{c_{p r i v}}$ & 0.046 & 0.050 & 0.006 & 0.243 \\
\hline
\end{tabular}

${ }^{a}$ The number of observations are $\mathrm{N}=1,711$ from 263 universities across 8 European countries. ${ }^{b}$ All variables are linearly interpolated across time, observations with missing values are dropped and zero values are replaced by 0.01 , thereby allowing for specialisation of universities in terms of teaching and research activities. Dropping linearly interpolated values or replacing zero values by $0.001,0.0001$ or the minimum value of the corresponding variable doesn't affect our qualitative results. These results are available from the authors upon request. ${ }^{c}$ Source: Aquameth datase (1994-2003).

tem in Italy, Spain and the UK relies heavily on tuition fees. Students in the UK, for example, contribute on average $25 \%$ to the university budget, which is the highest share of revenues that are financed by tuition fees among the analysed countries. The share of tuition fees is also relatively high in Italy and Spain, with mean values of $19 \%$ and $12 \%$, respectively, although the higher education system in both countries is largely publicly financed. Finally, the cross-correlations presented in Table A2 of the online appendix indicate that inputs and outputs are correlated to some extent with one another.

\section{Results}

\subsection{Main results}

Table 3 displays the six different model specifications of the simultaneous two-stage Stochastic Frontier Analysis we applied. The top panel displays the coefficient estimates of the output distance function as well as the impact of third-party funding on the production frontier. The middle panel shows the impact of third-party funding on 
the variance of inefficiency. The lower panel clarifies the treatment of unobserved heterogeneity and reverse causality by showing how the four models differ regarding the inclusion of country dummies, the use of lagged values and country averages of the budget shares. Specifically, Model 1 represents the base model. Model 2 extends the base model by adding country dummies, and Model 3 additionally lags budget shares by two years to account for reverse causality. Model 4 uses the averages of the budget shares across countries lagged by two years but includes no country dummies. Model 5 includes country dummies and uses the country averages of budget shares, i.e., exploiting withincountry variation over time. Finally, Model 6 lags the country averages of budget shares by two years.

Table 3: Estimation results of the output distance function using Stochastic Frontier Analysis ${ }^{a, b, c}$

\begin{tabular}{|c|c|c|c|c|c|c|c|}
\hline Variable & Parameter & Model 1 & Model 2 & Model 3 & Model 4 & Model 5 & Model 6 \\
\hline \multicolumn{8}{|c|}{ Production Frontier with publications, $\ln \left(Y_{p u b l}\right)$, as dependent variable } \\
\hline$Y_{\text {stud }}$ & $\alpha_{1}$ & $\begin{array}{c}-0.615^{* * *} \\
(0.015)\end{array}$ & $\begin{array}{c}-0.705^{* * *} \\
(0.018)\end{array}$ & $\begin{array}{c}-0.704^{* * *} \\
(0.019)\end{array}$ & $\begin{array}{c}-0.618^{* * *} \\
(0.016)\end{array}$ & $\begin{array}{c}-0.619^{* * *} \\
(0.015)\end{array}$ & $\begin{array}{c}-0.627^{* * *} \\
\left(\begin{array}{c}0.016)\end{array}\right.\end{array}$ \\
\hline$Y_{\text {stud }}^{2}$ & $\alpha_{11}$ & $\begin{array}{c}-0.079^{* * *} \\
\quad(0.003)\end{array}$ & $\begin{array}{c}-0.085^{* * *} \\
(0.003)\end{array}$ & $\begin{array}{c}-0.088^{* * *} \\
(0.004)\end{array}$ & $\begin{array}{c}-0.081^{* * *} \\
(0.004)\end{array}$ & $\begin{array}{c}-0.081^{* * *} \\
(0.003)\end{array}$ & $\begin{array}{c}-0.081^{* * *} \\
\left(\begin{array}{c}0.004)\end{array}\right.\end{array}$ \\
\hline$X_{\text {prof }}$ & $\beta_{1}$ & $\begin{array}{l}0.416^{* * *} \\
(0.013)\end{array}$ & $\begin{array}{l}0.384^{* * *} \\
(0.026)\end{array}$ & $\begin{array}{l}0.383^{* * *} \\
(0.028)\end{array}$ & $\begin{array}{l}0.429^{* * *} \\
(0.032)\end{array}$ & $\begin{array}{l}0.436^{* * *} \\
(0.029)\end{array}$ & $\begin{array}{c}0.463^{* * *} \\
\left(\begin{array}{c}0.030)\end{array}\right.\end{array}$ \\
\hline$X_{\text {res }}$ & $\beta_{2}$ & $\begin{array}{l}0.273^{* * *} \\
(0.021)\end{array}$ & $\begin{array}{l}0.366^{* * *} \\
(0.023)\end{array}$ & $\begin{array}{l}0.359^{* * *} \\
(0.028)\end{array}$ & $\begin{array}{l}0.349^{* * *} \\
(0.030)\end{array}$ & $\begin{array}{l}0.368^{* * *} \\
(0.027)\end{array}$ & $\begin{array}{c}0.345^{* * *} \\
\left(\begin{array}{c}0.029)\end{array}\right.\end{array}$ \\
\hline$X_{a d m}$ & $\beta_{3}$ & $\begin{array}{l}0.290^{* * *} \\
(0.028)\end{array}$ & $\begin{array}{l}0.213^{* * *} \\
(0.026)\end{array}$ & $\begin{array}{l}0.204^{* * *} \\
(0.035)\end{array}$ & $\begin{array}{l}0.206^{* * *} \\
(0.038)\end{array}$ & $\begin{array}{l}0.196^{* * *} \\
(0.032)\end{array}$ & $\begin{array}{c}0.186^{* * *} \\
\left(\begin{array}{c}0.034)\end{array}\right.\end{array}$ \\
\hline$X_{\text {prof }}^{2}$ & $\beta_{11}$ & $\begin{array}{l}0.056^{* * *} \\
(0.005)\end{array}$ & $\begin{array}{l}0.054^{* * *} \\
(0.009)\end{array}$ & $\begin{array}{l}0.015 \\
(0.024)\end{array}$ & $\begin{array}{l}0.021 \\
(0.032)\end{array}$ & $\begin{array}{l}0.069^{* * *} \\
(0.009)\end{array}$ & $\begin{array}{c}0.048^{*} \\
\left(\begin{array}{c}0.028)\end{array}\right)\end{array}$ \\
\hline$X_{\text {res }}^{2}$ & $\beta_{22}$ & $\begin{array}{l}0.017^{* * *} \\
(0.006)\end{array}$ & $\begin{array}{c}0.016^{* *} \\
(0.006)\end{array}$ & $\begin{array}{c}0.004 \\
(0.006)\end{array}$ & $\begin{array}{c}0.015^{* *} \\
\left(\begin{array}{c}0.007)\end{array}\right.\end{array}$ & $\begin{array}{r}0.018^{* *} \\
(0.009)\end{array}$ & $\begin{array}{l}0.009 \\
\left(\begin{array}{l}0.007)\end{array}\right)\end{array}$ \\
\hline$X_{a d m}^{2}$ & $\beta_{33}$ & $\begin{array}{l}0.194^{* * *} \\
(0.047)\end{array}$ & $\begin{array}{l}-0.017 \\
(0.045)\end{array}$ & $\begin{array}{l}0.045 \\
(0.065)\end{array}$ & $\begin{array}{l}0.050 \\
(0.063)\end{array}$ & $\begin{array}{l}-0.017 \\
(0.046)\end{array}$ & 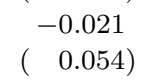 \\
\hline$X_{\text {prof }} * X_{\text {res }}$ & $\beta_{12}$ & $\begin{array}{c}-0.046^{* * *} \\
(0.014)\end{array}$ & $\begin{array}{c}-0.106^{* * *} \\
(0.014)\end{array}$ & $\begin{array}{c}-0.111^{* * *} \\
(0.016)\end{array}$ & $\begin{array}{c}-0.082^{* * *} \\
(0.018)\end{array}$ & $\begin{array}{c}-0.088^{* * *} \\
(0.015)\end{array}$ & 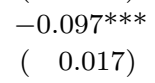 \\
\hline$X_{\text {prof }} * X_{a d m}$ & $\beta_{13}$ & $\begin{array}{c}-0.032^{* *} \\
(0.016)\end{array}$ & $\begin{array}{c}0.043^{* *} \\
(0.019)\end{array}$ & $\begin{array}{c}0.051^{* *} \\
(0.024)\end{array}$ & $\begin{array}{l}0.041 \\
(0.034)\end{array}$ & $\begin{array}{c}0.037^{* *} \\
(0.018)\end{array}$ & $\begin{array}{l}0.046 \\
(\quad 0.030)\end{array}$ \\
\hline$X_{r e s} * X_{a d m}$ & $\beta_{23}$ & $\begin{array}{r}-0.044^{* *} \\
(0.021)\end{array}$ & $\begin{array}{c}0.042^{* *} \\
(0.019)\end{array}$ & $\begin{array}{c}0.028 \\
(0.021)\end{array}$ & $\begin{array}{l}-0.016 \\
(\quad 0.023)\end{array}$ & $\begin{array}{l}-0.000 \\
(0.021)\end{array}$ & $\begin{array}{l}0.019 \\
\left(\begin{array}{l}0.022)\end{array}\right)\end{array}$ \\
\hline$Y_{\text {stud }} * X_{\text {prof }}$ & $\eta_{11}$ & $\begin{array}{c}-0.008^{* * *} \\
(0.003)\end{array}$ & $\begin{array}{c}-0.016^{* * *} \\
(0.003)\end{array}$ & $\begin{array}{c}-0.054^{* * *} \\
(0.020)\end{array}$ & $\begin{array}{c}-0.056^{* *} \\
(0.022)\end{array}$ & $\begin{array}{c}-0.010^{* * *} \\
(0.004)\end{array}$ & $\begin{array}{c}-0.060^{* * *} \\
\left(\begin{array}{c}0.019)\end{array}\right.\end{array}$ \\
\hline$Y_{\text {stud }} * X_{\text {res }}$ & $\eta_{12}$ & $\begin{array}{c}-0.103^{* * *} \\
(0.019)\end{array}$ & $\begin{array}{c}-0.119 * * * \\
\quad(0.014)\end{array}$ & $\begin{array}{c}-0.163^{* * *} \\
(0.027)\end{array}$ & $\begin{array}{c}-0.146^{* * *} \\
(0.021)\end{array}$ & $\begin{array}{c}-0.150^{* * *} \\
(0.020)\end{array}$ & 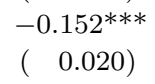 \\
\hline$Y_{\text {stud }} * X_{a d m}$ & $\eta_{13}$ & $\begin{array}{l}0.132^{* * *} \\
(0.021)\end{array}$ & $\begin{array}{l}0.129^{* * *} \\
(0.018)\end{array}$ & $\begin{array}{l}0.202^{* * *} \\
(0.042)\end{array}$ & $\begin{array}{l}0.186^{* * *} \\
(0.038)\end{array}$ & $\begin{array}{l}0.148^{* * *} \\
(0.023)\end{array}$ & 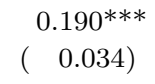 \\
\hline year $_{1995}$ & $\alpha_{1}$ & $\begin{array}{l}-0.052 \\
(0.058)\end{array}$ & $\begin{array}{l}-0.002 \\
(0.047)\end{array}$ & & & $\begin{array}{l}-0.048 \\
(0.067)\end{array}$ & \\
\hline year $_{1996}$ & $\alpha_{2}$ & $\begin{array}{c}0.034 \\
(0.050)\end{array}$ & $\begin{array}{c}0.034 \\
(0.042)\end{array}$ & 0.000 & 0.000 & $\begin{array}{l}-0.025 \\
(0.071)\end{array}$ & 0.000 \\
\hline year $_{1997}$ & $\alpha_{3}$ & $0.120 * *$ & 0.025 & 0.017 & -0.043 & -0.027 & -0.018 \\
\hline
\end{tabular}




\begin{tabular}{|c|c|c|c|c|c|c|c|}
\hline Variable & Parameter & Model 1 & Model 2 & Model 3 & Model 4 & Model 5 & Model 6 \\
\hline & & $(0.049)$ & $(0.041)$ & $(0.039)$ & $(0.063)$ & $(0.065)$ & $(0.063)$ \\
\hline \multirow[t]{2}{*}{ year $_{1998}$} & $\alpha_{4}$ & $0.130^{* * *}$ & 0.014 & 0.037 & 0.001 & -0.015 & 0.013 \\
\hline & & $(0.049)$ & $(0.041)$ & ( 0.038$)$ & $(0.054)$ & $(0.065)$ & $(0.071)$ \\
\hline \multirow[t]{2}{*}{ year $_{1999}$} & $\alpha_{5}$ & $0.089^{*}$ & 0.002 & 0.018 & 0.091 & -0.041 & 0.055 \\
\hline & & $(0.047)$ & $(0.039)$ & ( 0.037$)$ & $(0.057)$ & $(0.071)$ & $(0.065)$ \\
\hline \multirow[t]{2}{*}{ year $_{2000}$} & $\alpha_{6}$ & -0.011 & -0.023 & -0.030 & 0.004 & -0.053 & 0.021 \\
\hline & & $(0.047)$ & $(0.040)$ & ( 0.038$)$ & $(0.056)$ & $(0.076)$ & $(0.065)$ \\
\hline \multirow[t]{2}{*}{ year $_{2001}$} & $\alpha_{7}$ & 0.050 & 0.029 & 0.037 & 0.080 & 0.004 & 0.132 \\
\hline & & $(0.048)$ & $(0.041)$ & $(0.039)$ & $(0.065)$ & $(0.079)$ & $(0.090)$ \\
\hline \multirow[t]{2}{*}{ year $_{2002}$} & $\alpha_{8}$ & 0.047 & 0.033 & 0.036 & 0.068 & -0.015 & 0.157 \\
\hline & & $(0.049)$ & $(0.042)$ & $(0.040)$ & $(0.069)$ & $(0.080)$ & $(0.102)$ \\
\hline \multirow[t]{2}{*}{ year $_{2003}$} & $\alpha_{9}$ & 0.067 & 0.059 & $0.099^{*}$ & $0.172^{* *}$ & 0.108 & $0.245^{*}$ \\
\hline & & $(0.062)$ & $(0.057)$ & $(0.056)$ & $(0.079)$ & $(0.102)$ & $(0.127)$ \\
\hline \multirow{2}{*}{$b s h a_{\text {pubint }}$} & $\gamma_{1}$ & $-0.118^{* * *}$ & $-0.089 * * *$ & $-0.093^{* * *}$ & $-0.319 * * *$ & -0.008 & -0.107 \\
\hline & & $(0.019)$ & $(0.014)$ & $(0.016)$ & $(0.070)$ & $(0.046)$ & $(0.081)$ \\
\hline \multirow[t]{2}{*}{$b s h a_{\text {pubint }}^{2}$} & $\gamma_{12}$ & $-0.023^{* *}$ & $-0.016^{* *}$ & $-0.031^{* * *}$ & -0.082 & -0.050 & -0.115 \\
\hline & & $(0.010)$ & $(0.008)$ & $(0.009)$ & $(0.115)$ & $(0.052)$ & $(0.090)$ \\
\hline \multirow[t]{2}{*}{$b s h a_{\text {priv }}$} & $\gamma_{2}$ & $0.057^{* *}$ & 0.017 & 0.010 & 0.044 & -0.102 & $-0.222^{*}$ \\
\hline & & $(0.023)$ & $(0.017)$ & $(0.020)$ & $(0.054)$ & $(0.068)$ & $(0.126)$ \\
\hline \multirow{2}{*}{$b s h a_{p r i v}^{2}$} & $\gamma_{22}$ & $-0.027^{* *}$ & $-0.032^{* * *}$ & $-0.045^{* * *}$ & 0.138 & -0.126 & 0.076 \\
\hline & & $(0.012)$ & $(0.008)$ & $(0.012)$ & ( 0.103$)$ & $(0.083)$ & $(0.146)$ \\
\hline \multirow[t]{2}{*}{ bshatuit } & $\gamma_{3}$ & $0.214^{* * *}$ & $0.522^{* * *}$ & $0.442^{* * *}$ & $0.197^{*}$ & $0.691 *$ & 0.480 \\
\hline & & $(0.043)$ & $(0.043)$ & $(0.046)$ & $(0.118)$ & $(0.406)$ & $(0.530)$ \\
\hline \multirow[t]{2}{*}{$b s h a_{\text {tuit }}^{2}$} & $\gamma_{33}$ & $0.119^{* * *}$ & $0.201^{* * *}$ & $0.160^{* * *}$ & $0.105^{*}$ & 0.332 & 0.266 \\
\hline & & $(0.029)$ & $(0.030)$ & $(0.027)$ & $(0.057)$ & $(0.222)$ & $(0.290)$ \\
\hline \multirow[t]{2}{*}{ Constant } & $\alpha_{0}$ & $0.228 * * *$ & $0.757 * * *$ & $0.772^{* * *}$ & $0.178^{* *}$ & $1.255^{* * *}$ & $0.791^{*}$ \\
\hline & & $(0.050)$ & $(0.091)$ & $(0.097)$ & $(0.072)$ & $(0.306)$ & $(0.439)$ \\
\hline \multicolumn{8}{|c|}{ Inefficiency Equation with $\sigma_{u}^{2}$ as dependent variable } \\
\hline \multirow[t]{2}{*}{ bsha $a_{\text {pubint }}$} & $\delta_{r_{1}}$ & $-0.799^{* * *}$ & $-0.935^{* * *}$ & $-0.744^{* * *}$ & $-2.277^{* * *}$ & 5.794 & -0.180 \\
\hline & & $(0.261)$ & $(0.252)$ & $(0.273)$ & $(0.502)$ & ( 3.839$)$ & $(2.843)$ \\
\hline \multirow[t]{2}{*}{$b s h a_{\text {pubint }}^{2}$} & $\delta_{r_{12}}$ & -0.189 & -0.227 & $-0.404^{* *}$ & $-1.264^{* * *}$ & $-8.928^{*}$ & -18.441 \\
\hline & & $(0.132)$ & $(0.143)$ & $(0.165)$ & $(0.422)$ & $(5.165)$ & ( 20.758) \\
\hline \multirow[t]{2}{*}{$b s h a_{\text {priv }}$} & $\delta_{r_{2}}$ & 0.210 & $0.474^{*}$ & $0.448^{* *}$ & $7.929 * * *$ & $1.882^{* *}$ & 8.510 \\
\hline & & $(0.252)$ & $(0.258)$ & $(0.192)$ & $(1.609)$ & $(0.791)$ & $(5.369)$ \\
\hline \multirow[t]{2}{*}{$b s h a_{\text {priv }}^{2}$} & $\delta_{r_{22}}$ & $-0.749^{* * *}$ & $-0.902^{* * *}$ & $-0.674^{* * *}$ & $-9.997^{* * *}$ & $1.896^{* *}$ & -2.638 \\
\hline & & ( 0.148$)$ & $(0.275)$ & ( 0.190$)$ & $(1.704)$ & $(0.931)$ & $(5.536)$ \\
\hline \multirow[t]{2}{*}{$b s h a_{t u i t}$} & $\delta_{r_{3}}$ & $1.073^{* * *}$ & $2.140^{* * *}$ & $1.789^{* * *}$ & $3.862^{* * *}$ & $8.745^{* * *}$ & $7.809^{* *}$ \\
\hline & & $(0.276)$ & $(0.228)$ & $(0.318)$ & $(1.115)$ & $(3.287)$ & $(3.626)$ \\
\hline \multirow[t]{2}{*}{$b s h a_{\text {tuit }}^{2}$} & $\delta_{r_{33}}$ & $1.022^{* * *}$ & $1.429 * * *$ & $1.090^{* * *}$ & $3.655^{* * *}$ & $4.545^{* * *}$ & 3.832 \\
\hline & & $(0.209)$ & $(0.244)$ & $(0.297)$ & $(0.771)$ & $(1.678)$ & $(2.415)$ \\
\hline \multirow[t]{2}{*}{ Constant } & $\psi_{0}$ & $-1.587^{* * *}$ & $-2.010^{* * *}$ & $-1.607^{* * *}$ & $-2.794^{* * *}$ & $-3.375^{* * *}$ & $-3.654^{* * *}$ \\
\hline & & $(0.262)$ & $(0.292)$ & $(0.280)$ & $(0.359)$ & $(0.753)$ & $(1.230)$ \\
\hline $\mathrm{N}$ & & 1,711 & 1,711 & 1,280 & 1,297 & 1,711 & 1,280 \\
\hline Year dummies & & yes & yes & yes & yes & yes & yes \\
\hline Country dummies & & no & yes & yes & no & yes & yes \\
\hline Lagged values & & no & no & yes & yes & no & yes \\
\hline Country averages & & no & no & no & yes & yes & yes \\
\hline
\end{tabular}




\begin{tabular}{|c|c|c|c|c|c|c|c|}
\hline Variable & Parameter & Model 1 & Model 2 & Model 3 & Model 4 & Model 5 & Model 6 \\
\hline
\end{tabular}

The coefficients of the outputs and inputs that are shown in the top panel of Table 3 behave well in the sense that the first-order coefficients are significant and have the expected signs across all six models. This result demonstrates the validity of our input distance function specification. The coefficient of the output variable $\left(Y_{\text {stud }}\right)$ is negative, whereas the coefficients of the input variables $\left(X_{\text {prof }}, X_{\text {res }}, X_{a d m}\right)$ are positive. Furthermore, the magnitude of the coefficients remains stable across all models.

The coefficient for the quadratic number of students $\left(Y_{\text {stud }}^{2}\right)$ is also negative and indicates unexploited economies of scale. This is important because assuming that acquiring external funding increases the university budget, an increase in the share of the budget financed by external funding increases productivity because of the exploitation of these economies of scale. As our production function captures this effect, these productivity gains will arise in addition to the results captured in our model.

The overall trends are captured in the year dummies (year ${ }_{1995}$ to year $_{2003}$ ), which suggests that technological change has been largely absent in the observed time period, although this may be driven by the unbalanced nature of our panel.

The upper panel of Table 3 further shows that the international public funding share reduces the production frontier. Both the linear and quadratic coefficients are significantly negative in the first four models and remain negative in Models 5 and 6 , which may be because the available variation is insufficient to perform such a complex estimation. This result suggests the existence of an administration effect that dominates a potential competition or sorting effect. This finding indicates that control mechanisms should be streamlined for international public funding as the impact on the production function is negative. Our results reflect the findings of [58], who shows in a comparative, interview-based study of experimental physicists working at Australian and German universities that the researcher's criteria for selecting funding agencies refer to the effort that is caused by grant applications, report procedures, and a rough success rate for obtaining external funds. For example, the funding procedure of the European Union - as many of the interviewees stated - has very low success rates in addition to being perceived as being extremely bureaucratic concerning application and reporting procedures.

Although the bureaucracy of funding procedures burden universities with administrative effort, control mechanisms also appear to discipline universities to increase efficiency in the production process. The significantly negative coefficients in the middle panel of Table 3 suggests that the international public funding share decreases the variance of inefficiency and therefore increases average efficiency. The coefficient of the squared term is significantly negative in Models 1, 2 and 3. The coefficients of both the linear and

\footnotetext{
${ }^{20}$ Using the number of enrolled students, $Y_{\text {stud }}$, as normalizing output instead qualitatively yields the same results. These results can be obtained from the authors upon request.
} 
quadratic terms remain insignificant in Models 4 and 5, whereas the squared term again turns significantly negative in Model 6 . This result provides evidence for the competition effect, that is, increasing competition for international public funding sources raises university efficiency. Although these results do not rule out the presence of a sorting effect, the dominance of the administration effect for the production frontier and the competition effect for efficiency suggests that the sorting effect remains relatively weak for international public funding. Consistent with a fundamental motivation that underlies the reform processes of the European higher education sector, our finding indicates that intensifying the competition of external funding disciplines universities to operate more efficiently. Universities that operate below the production frontier catch up to the production frontier of best practice. ${ }^{21}$

In terms of international public funds, our results suggest that external funding sources should use performance-based control instruments related to the research outcome. These instruments include targeted funding and performance measures rather than extensive, complex and confusing reporting structures. In other words, funding agencies should introduce the 'right' instruments that discipline researchers to operate efficiently but do not burden them with unnecessary administrative tasks. In fact, the European Commission recently declared major improvements in the EU research and innovation funding mechanism that attempt to simplify the procedures, which will make participation easier, increase scientific and economic impacts and improve value [36, 35].

Table 3 reveals ambiguous evidence regarding the impact of the private funding share on the production frontier. While the linear term is positive but mostly insignificant, the squared term has a significant negative coefficient in Models 1-3, which tends to suggest an inverse $\mathrm{u}$-shaped effect of the private funding share on the production frontier. These results point to the presence of a competition or sorting effect in addition to an administration effect. Either the competition or sorting effect dominates for low levels of private funds, whereas the administration effect becomes relatively more important as the share of private funds increases. However, using country averages to account for within-country heterogeneity, these coefficients become insignificant, and the quadratic term becomes positive, which questions the causal impact of the private funding share on the production frontier. This result may indicate that the monitoring process of private donors may be less costly compared with the process that is used for international public funding. An alternative explanation could be that the competition or sorting effect may be stronger for private funding than for international public funding. However, this relation is questioned by the insignificance of both coefficient estimates in Model 4 and the change in the relation that is visible in Models 5 and 6 .

Furthermore, the private funding share indicates an inverse u-shaped impact on the spread of university inefficiency because the linear term turns out positive, whereas the quadratic term is negative except in Model 5. This u-shaped effect of the private funding

\footnotetext{
${ }^{21}$ The results remain qualitatively robust if assuming an input distance function instead of an output distance function, although standard errors explode in estimates using the lagged share of country averages (Models 4 and 6), rendering the estimates insignificant.
} 
share on university efficiency implies that private funds affect efficiency negatively for low levels and positively for high levels of private funding. This finding suggests that the sorting effect dominates for low levels of private funding share, but the competition effect prevails for high levels of the budget share that is financed by private funding. [20], in contrast, find an inverse u-shaped impact of private funding share on efficiency. This difference may arise because their sample covers a substantially smaller range of funding shares. Additionally, the linear relation that is presumed in [22] may explain why they observe no impact of the private funding share. An alternative explanation of our result of a decline in efficiency could be a misspecification in our production function. Concretely, as universities begin to acquire private funds, they may place an increasing focus on applied research rather than basic research. Assuming that our measures capture this output dimension insufficiently provides a potential explanation for an observed decline in efficiency. The results that use an input distance function instead of an output distance function support this explanation, as the impact of private budget shares on the spread of inefficiency becomes negative rather than inversely ushaped. This finding may suggest that private funding improves the efficient use of existing funds but does not generate more output in terms of publications and students.

Referring to tuition fees, Table 3 shows that the tuition fee share increases the production frontier because both the linear and squared terms are positive and highly significant across the first five models and remain positive although insignificant in Model 6. An increase in the tuition fees raises the productivity of the best performing universities, that is, the production frontier shifts outward. This finding aligns with our theoretical framework that predicts the presence of a competition or sorting effect. However, it also suggests that the administration effect is smaller for tuition fees because many efforts to increase reputation occur at the university level, and parents and prospective students bear a larger share of the monitoring costs.

We further find that the tuition fee share decreases efficiency, which the positive and significant coefficients for the impact on the variance of inefficiency show. The sorting effect dominates a potential competition effect regarding efficiency. This finding is particularly relevant given the empirical evidence that a competition effect exists, as [1] and [2] find a positive impact of competition on efficiency for Australia and Italy, respectively.

The dominance of the sorting effect over the competition effect concerning efficiency also suggests that the positive impact of the tuition fee share on the production frontier discussed earlier arises because of a sorting effect, not a competition effect, which is presumably weaker at the frontier than below. An increase in tuition fees not only raises the production frontier of the best practice but also increases the spread between the best and worst performing universities. Highly skilled researchers and students are sorted into the most productive universities. ${ }^{22}$

\footnotetext{
${ }^{22}$ The results remain generally robust if assuming an input distance function instead of an output distance function except in the estimates using the lagged share of country averages
} 
These findings are based on an analysis where university productivity is estimated relative to the outer boundary of production. The results do not rule out the possibility that universities that operate below the frontier may improve their productivity from the introduction of tuition fees. The results merely show that the spread between the best and the worst performing university increases.

\subsection{Robustness analyses}

To evaluate the robustness of our results in terms of multicollinearity, we run six additional model specifications. The results are reported in Table A3 in the online appendix. To facilitate a comparison across the tables, Model 4 repeats the estimates of Model 2 of Table 3. The remaining columns of Table A3 show model specifications that allow us to analyse the relevance of multicollinearity among the three budget share variables and whether their inclusion in the two estimation stages matters. Models 1-3 include budget shares that are financed by international public funds, private funds and tuition fees separately in both the frontier and the inefficiency equations. Models 5 and 6 include all budget share types either in the frontier or inefficiency equation, respectively. Finally, Model 7 contains all budget share types in both equations and includes the interactions of the input variables, $X$, and output variables, $Y$, with the budget share variables in the frontier equation. We find that our results remain qualitatively robust to these variations in the model specifications.

Furthermore, Table A4 in the online appendix reports the results of a robustness check regarding the sample by excluding individual countries. Model 1 includes all eight countries and repeats the estimates of Model 2 of Table 3. Eliminating a country in each remaining model qualitatively yields the same results. The UK represents the only exception. Because of the substantial reduction in the sample size, the coefficients in the inefficiency equation turn insignificant in this model, although the parameter estimates actually increase in magnitude.

Finally, Table A5 in the online appendix shows estimates that allow us to assess the robustness of the results in two directions. First, the results test whether the results are robust to changing the specification of how budget shares affect efficiency. Second, the model allows to cluster standard errors on the level of universities and countries, allowing to test the robustness of inference regarding the clustering of standard errors. ${ }^{23}$ Instead of modelling the variance of inefficiency as a function of budget shares, $\left(u_{i t} \sim\right.$ iid $\left.N^{+}\left[0, \sigma_{u}\left(z_{s i t}\right)^{2}\right]\right)$, we follow [15] and model the truncation point of a truncated half-normal distribution as a function of budget shares, $\left(u_{i t} \sim \operatorname{iid} N^{+}\left[\mu_{u}\left(z_{s i t}\right), \sigma_{u}^{2}\right]\right)$, where $\mu_{u}\left(z_{s i t}\right)$ is modelled as a function of budget shares, $z_{s i t}$, and an error term, $\omega_{i t}$, with mean 0 :

(Models 4 and 6). In this case, tuition fees no longer have an effect on the production frontier but decrease the spread of inefficiency.

${ }^{23}$ The Stata frontier command that is used in the main estimation does not allow for clustered standard errors. 


$$
\mu_{i t}=\gamma_{s} z_{s i t}+\omega_{i t}
$$

Corresponding to the Table 3, Table A5 in the online appendix shows the results of five approaches that account for potential endogeneity by including country dummies, lagging budget share values and using country averages of budget shares. ${ }^{24}$ Table A5 reports coefficient estimates and three sets of standard errors. Concretely, the first standard errors are not heteroscedasticity adjusted. ${ }^{25}$ The two sets of standard errors shown below refer to standard errors clustered at the university level and standard errors clustered at the country level. Models 1-3 are very similar to the baseline estimates, which supports the robustness of our results in terms of the effect. Furthermore, statistical inference is similar in the case of clustered standard errors, suggesting that inference in the main models is robust, too. However, the estimates for budget shares turn insignificant in Model 4. Furthermore, the coefficient estimates for tuition fees have a different sign. This is particularly surprising, as Model 5 yields similar coefficient estimates as Models 1-3. While the estimates for international public funds are significant in the case of clustered standard errors, the estimates for tuition fees remain insignificant. Nevertheless, the overall robustness of the findings regarding the specification of the efficiency equation and standard errors suggests that the main results presented in Table 3 represent statistically valid estimates.

\section{Conclusion}

This paper analyses the effect of competitive funding on university production. For this purpose, we develop a simple theoretical framework for the differential effect of three competitive funding sources on the production frontier of best-practice and the spread of university efficiency. These funding sources are international public funds, private funds and tuition fees. To test our framework empirically, we apply the concept of frontier measures and estimate a simultaneous two-stage Stochastic Frontier Analysis based on an unbalanced university-level panel dataset across 8 European countries.

Our results provide evidence for the existence of differential effects of competitive funding on the production frontier of best practice and the spread of university efficiency. This finding suggests that introducing competitive funding schemes in the university sector involves a trade-off that should be considered by politicians. In particular, our findings indicate different implications for the organisation of a higher education system depending on the objectives that governmental authorities focus on.

\footnotetext{
${ }^{24}$ The estimation for Model 6, i.e. including country dummies and using lagged values of country averages across budget shares fail to converge.

${ }^{25}$ Hence, a direct comparison with the models in Table 3 is not possible because robust standard errors in this model are always clustered at university level. Preliminary analysis suggests that in the main model robust standard errors are about 1.5 to 2 times the magnitude of non-adjusted errors. Since non-adjusted and university clustered standard errors have a similar relationship, the findings suggest that inference based on robust standard errors yields reasonable results.
} 
If the governmental authorities intend to establish a higher education system that is based on excellence and 'internationally visible beacons', our results suggest that competitive funding in terms of tuition fees should be introduced because they induce the sorting of the best talents to top universities. In particular, it strengthens the best performing universities because they can select the most talented researchers and students. Therefore, the production frontier shifts outward, and the deviation to it increases. The best performing universities become better, whereas other universities may be limited in their ability to catch up to the production frontier.

Given the sorting effect of tuition fees that favour talented students, it emphasises the relevance of the discussion on providing income-contingent student credits and scholarships for the brightest students regardless of their background [see, e.g., 83]. However, one argument against the sorting of students may be the existence of asymmetric peer effects [see, e.g., 84, 37, 55]. That is, a more heterogeneous student composition may be beneficial to rather weak students and not detrimental to good students. In this case, introducing tuition fees may be detrimental to the average ability of the graduates who enter the labour market. Moreover, increasing the tracking of students induced by introducing tuition fees may increase the gap between low- and high-achieving students. Equity concerning access to higher education may represent an additional argument against the introduction of tuition fees. The establishment of tuition fees in a higher education system is a highly disputed topic in political and social discussions in many European countries. It is beyond the scope of this paper to engage in this debate.

If governmental authorities intend to decrease the spread between the best and the worst universities, our results suggest that instruments should be applied that foster the catching up of universities to best-practice. Recalling the prior findings of this study suggests the strengthening of competition by increasing the relevance of international public and private funds. This suggestion is because of the positive effect on university efficiency, which is likely caused by a competition effect. Therefore, one may argue that governmental authorities should not only emphasise especially these competitive funding resources but also consider the need to reduce the administrative effort. In our sample, the average budget shares that are financed by international public and private funds are only $2.3 \%$ and $4.7 \%$, respectively, of the budget. Therefore, substantial space exists to expand financing through international public funds (e.g., European Union) and the private sector (industry, agencies, foundations, and private donors). The adoption of financial, fiscal and legal frameworks may stimulate these actors to allocate more funds to university education and research. Nevertheless, it remains a political debate whether and to what extent such financial funding concepts should be established.

Although this study provides an initial attempt at providing evidence of the differential effects of competitive university funding, a number of shortcomings incite further research on this topic. Our analysis does not involve the arguably most important source of competitive funding, namely, competitive funding from national public sources. Furthermore, extending the sample to other countries would help to establish the external validity of our findings. Moreover, because of data availability, we employ a simple output distance function, which implies that future research should test whether more com- 
prehensive production function specifications yield the same results. This need is particularly true because our university level estimation may mask unobserved heterogeneity across departments in a university. Therefore, using an alternative research design may root out remaining doubts about a causal interpretation of our identification strategy, e.g., regarding potentially omitted variable bias in the inefficiency equation. Finally, although our results clarify the trade-offs that political authorities face, politicians also require information concerning the aggregate productivity effects of competitive funding schemes. These results would help policy-makers to determine how a third-party funding system should be organised to ensure the optimal allocation of resources in the higher education sector. 


\section{References}

[1] Abbott, M. and Doucouliagos, C. (2009). Competition and efficiency: overseas students and technical efficiency in Australian and New Zealand universities. Education Economics, 17(1):31-57.

[2] Agasisti, T. (2009). Market forces and competition in university systems: Theoretical reflections and empirical evidence from Italy. International Review of Applied Economics, 23:463-483.

[3] Agasisti, T. and Johnes, G. (2009). Beyond frontiers: Comparing the efficiency of higher education decision-making units across more than one country. Lancaster Working Paper Series, 13.

[4] Agasisti, T. and Pohl, C. (2012). Comparing german and italian public universities: Convergence or divergence in the higher education landscape? Managerial and Decision Economics, 33:71-85.

[5] Agasisti, T. and Pérez-Esparrells, C. (2009). Comparing effciency in a cross-country perspective: the case ofItalian and Spanish state universities. Higher Education, Online First.

[6] Aghion, P., Dewatripont, M., Hoxby, C., Mas-Colell, A., and Sapir, A. (2008). Higher aspirations: An agenda for reforming European universities. Bruegel Blueprints.

[7] Aghion, P., Dewatripont, M., Hoxby, C. M., Mas-Colell, A., and Sapir, A. (2009). The governance and performance of research universities: Evidence from Europe and the U.S. NBER Working Paper 14851.

[8] Aghion, P., Dewatripont, M., Hoxby, C. M., Mas-Colell, A., and Sapir, A. (2010). The governance and performance of research universities: Evidence from Europe and the U.S. Economic Policy, 25(6):7-59.

[9] Aigner, D., Lovell, C. K., and Schmidt, P. (1977). Formulation and estimation of stochastic frontier production models. Journal of Econometrics, 6:21-37.

[10] Arrow, K. (1985). The economics of agency. In Pratt, J. and Zeckhauser, R., editors, Principals and agents: The structure of business, pages 37-51. Boston: Harvard Business School Press.

[11] Auranen, O. and Nieminen, M. (2010). University research funding and publication performance - An international comparison. Research Policy, 39:822-834.

[12] Badin, L., Daraio, C., and Simar, L. (2012a). Explaining inefficiency in nonparametric production models: the state of the art. Annals of Operations Research, DOI 10.1007/s10479-012-1173-7. 
[13] Badin, L., Daraio, C., and Simar, L. (2012b). How to measure the impact of environmental factors in a nonparametric production model. European Journal of Operational Research, DOI 10.1016/j.ejor.2012.06.028.

[14] Banker, R. (1986). Efficiency analysis for exogenously fixed inputs and outputs. Operations Research, 34:513-521.

[15] Battese, G. E. and Coelli, T. J. (1995). A model for technical inefficiency effects in a stochastic frontier production function for panel data. Empirical Economics, 20(2):325-32.

[16] Black, D. A. and Smith, J. (2004). How robust is the evidence on the effects of college quality? Evidence from matching. Journal of Econometrics, 121:99-124.

[17] Bolli, T. and Somogyi, F. (2011). Do competitively acquired funds induce universities to increase productivity? Research Policy, 40:136-147.

[18] Bonaccorsi, A. and Daraio, C. (2004). Econometric approaches to the analysis of producitivity of $\mathrm{r} \& \mathrm{~d}$ systems: production functions and production frontiers. In Moed, H., Glanzel, W., and Schmoch, U., editors, Handbook of quantitative science and technology research, pages 51-74. Kluwer Academic Publishers.

[19] Bonaccorsi, A. and Daraio, C., editors (2007). Universities and strategic knowledge creation. Specialization and performance in Europe. Edward Elgar, Cheltenham.

[20] Bonaccorsi, A., Daraio, C., and Simar, L. (2006). Advanced indicators of productivity of universities. An application of robust nonparametric methods to Italian data. Scientomtrics, 66(2):389-410.

[21] Butler, L. (2003). Explaining Australia's increased share of isi publications - The effects of a funding formula based on publication counts. Research Policy, 32(1):143155 .

[22] Carayol, N. and Matt, M. (2006). Individual and collective determinants of academic scientists' productivity. Information Economics and Policy, 18(1):55-72.

[23] Carrico, C., Hogan, S., Dyson, R. G., and Athanssopoulos, A. (1997). Data envelopment analysis and university selection. The Journal of the Operational Research Society, 48(12):1163-1177.

[24] Caudill, S. B., Ford, J. M., and Gropper, D. M. (1995). Frontier estimation and firm-specific inefficiency measures in the presence of heteroscedasticity. Journal of Business 8 Economic Statistic, 13(1):105-111.

[25] Cherchye, L. and Abeele, P. V. (2005). On research efficiency: A micro-analysis of Dutch university research in economics and business management. Research Policy, 34(4):495-516. 
[26] Clarke, M. (2007). The impact of higher education rankings on student access, choice, and opportunity. Higher Education in Europe, 32(1):59-70.

[27] Coelli, T., Rao, D., O'Donnell, C., and Battese, C. (2005). An introduction to efficiency and productivity analysis. Springer, 2nd edition.

[28] Coelli, T. J. (2000). On the econometric estimation of the distance function representation of a production technology. Universit'e Catholique de Louvain - Center for Operations Research and Economics, Louvain-la-Neuve, Belgium.

[29] Cook, P. J. and Frank, R. H. (1993). The growing concentration of top students at elite schools. In Studies of supply and demand in higher education, pages 121-144. University of Chicago Press.

[30] Coupé, T., Smeets, V., and Warzynski, F. (2003). Incentives in economic departments: Testing tournaments? Technical report, ISSN 1397-4831, Working Paper 03 -25, Department of Economics of Aarhus School of Business.

[31] Daraio, C., Bonaccorsi, A., Geuna, A., Leporic, B., Bach, L., Bogetoft, P., Cardoso, M. F., Castro-Martinez, E., Crespi, G., Fernandez de Lucio, I., Fried, H., GarciaAracil, A., Inzelt, A., Jongbloed, B., Kempkes, G., Llerena, P., Matt, M., Olivares, M., Pohl, C., Raty, T., Rosas, M., Sarrico, C., Simar, L., Slipersaeter, S., Teixeira, P., and Vanen Eeckaut, P. (2011). The European university landscape: A micro characterization based on evidence from the Aquameth project. Research Policy, 40:148-164.

[32] Daraio, C. and Simar, L. (2005). Introducing environmental variables in nonparametric frontier models: a probabilistic approach. Journal of Productivity Analysis, 24:93-121.

[33] Daraio, C. and Simar, L. (2007). Advanced robust and nonparametric methods in effciency analysis: Methodology and applications. New York: Springer.

[34] De Boer, H. and File, J. (2009). Higher education governance reforms across Europe. Technical report, University of Twente.

[35] European Commission (2010). Simplifying the implementation of the research framework programmes. Communication from the Commission, $\operatorname{COM}(2010) 187$.

[36] European Commission (2011). EU research and innovation funding: Commission consults on radical changes to create more growth and jobs. Press Release, IP/11/138, Brussels, February 9 , 2011.

[37] Falk, A. and Ichino, A. (2006). Clean evidence on peer effects. Journal of Labor Economics, 24(1):39-58. 
[38] Farrell, M. (1957). The measurement of technical efficiency. Journal of the Royal Statistical Society, Series A,(General, 120, Part 3):253-281.

[39] Federkeil, G. (2002). Some aspects of ranking methodology - the CHE-ranking of German universities. Higher Education in Europe, 27(4):389-397.

[40] Fenn, P., Vencappa, D., Diacon, S., Klumpes, P., and O'Brien, C. (2008). Market structure and the efficiency of European insurance companies: A stochastic frontier analysis. Journal of Banking \& Finance, 32(1):86-100.

[41] Färe, R. and Primont, D. (1995). Multi-output production and duality: Theory and applications. Kluwer Academic Publishers, Boston.

[42] Fried, H., Lovel, K., and Schmidt, S., editors (2008). The measurement of productive efficiency and productitiy growth. Oxford University Press.

[43] García-Aracil, A. and Palomares-Montero, D. (2008). Evaluation of spanish universities: Efficiency, technology and productivity chang. In Prime-Latin America Conference.

[44] Greene, W. (2005a). Fixed and random effects in stochastic frontier models. Journal of Productivity Analysis, 23:7-32.

[45] Greene, W. (2005b). Reconsidering heterogeneity in panel data estimators of the stochastic frontier model. Journal of Econometrics, 126:269-303.

[46] Howard, M. (2002). Student use of rankings in national magazines in the college decisionmaking process. $\mathrm{PhD}$ thesis, The University of Tennessee, Knoxville.

[47] Izadi, H., Johnes, G., Oskrochi, R., and Crouchley, R. (2002). Stochastic frontier estimation of a CES cost function: The case of higher education in Britain. Economics of Education Review, 21(1):63-71.

[48] Jensen, M. C. and Meckling, W. H. (1976). Theory of the firm: Managerial behavior, agency costs and ownership structure. Journal of Financial Economics, 3(4):305-360.

[49] Johnes, G. and Johnes, J. (2009). Higher education institutions' costs and effciency: Taking the decomposition a further step. Economics of Education Review, 28:107-113.

[50] Johnes, J. (2004). Efficiency measurement. In Johnes, G. and Johnes, J., editors, The International Handbook on the Economics of Education. Edward Elgar.

[51] Johnes, J. (2006). Data envelopment analysis and its application to the measurement of efficiency in higher education. Economics of Education Review, 25:273-288.

[52] Johnes, J. (2014). Efficiency and merger in english higher education 1996/97 to 2008/2009: Parametric and non-parametric estimation of the multi-input multioutput distance function. The Manchester School, 82:465-487. 
[53] Jongbloed, B. (2003). Marketisation in higher education, Clark's triangle and the essential ingredients of markets. Higher Education Quarterly, 57(2):110-135.

[54] Joumady, O. and Ris, C. (2005). Performance in european higher education: A non-parametric production frontier approach. Education Economics, 13:189-205.

[55] Kiss, D. (2011). The impact of peer ability and heterogeneity on student achievement: Evidence from a natural experiment. (02/2011).

[56] Kivistö, J. (2005). The government-higher education institution relationship: Theoretical considerations from the perspective of agency theory. Tertiary Education and Management, 11:1-17.

[57] Kuo, H. and Ho, Y. (2007). The cost efficiency impact of the university operation fund on public universities in Taiwan. Economics of Education Review, 27:603-612.

[58] Laudel, G. (2006). The art of getting funded: How scientists adapt to their funding conditions. Science and Public Policy,, 33(7):489-504.

[59] Leach, L. and Zepke, N. (2005). Student decision-making by prospective tertiary students. A review of existing New Zealand and overseas literature. Technical report, Ministry of Education, New Zealand. Report to the Ministry of Education.

[60] Lenton, P. (2008). The cost structure of higher education in further education colleges in england. Economics of Education Review, 27:471-482.

[61] McMillan, M. and Chan, W. (2006). University efficiency: A comparison and consolidation of results from stochastic and non-stochastic methods. Education Economics, $14: 1-30$.

[62] Meeusen, W. and van den Broeck, J. (1977). Efficiency estimation from cobbdouglas production functions with composed error. International Economic Review, 18:435-444.

[63] Mensah, Y. M. and Werner, R. (2003). Cost efficiency and financial flexibility in institutions of higher education. Journal of Accounting and Public Policy, 22(4):293323.

[64] Ness, E. C. (2010). The role of information in the policy process: Implications for the examination of research utilization in higher education policy. In Smart, J., editor, Higher Education: Handbook of Theory and Research, volume 25, pages 1-49. Springer.

[65] Niskanen, W. (1971). Bureaucracy in representative government. Aldine-Atherton, New York. 
[66] Niskanen, W. (1975). Bureaucrats and politicians. Journal of Law and Economics, 18(3):617-643.

[67] Olesen, O. and Peterson, N. (2009). Target and technical efficiency in dea: controlling for environmental characteristics. Journal of Productivity Analysis, 32:27-40.

[68] Parteka, A. and J., W.-D. (2013). Dynamics of productivity in higher education: Cross-european evidence based on bootstrapped malmquist indices. Journal of Productivity Analysis, 40:67-82.

[69] Pascoe, S., Punt, A., and Dichmont, C. (2010). Targeting ability and output controls in Australia's multi-species northern prawn fishery. European Review of Agricultural Economics, 37(3):313-334.

[70] Paul, C. J., Johnston, W. E., and Frengley, G. A. (2000). Efficiency in new zealand sheep and beef farming: The impacts of regulatory reform. The Review of Economics and Statistics, $82(2): 325-337$.

[71] Ray, S. (1988). Data envelopment analysis, nondiscretionary inputs and efficiency: an alternative interpretation. Socio-Economic Planning Sciences, 22:167-176.

[72] Reifschnieder, D. and Stevenson, R. (1991). Systematic departures from the frontier: a framework for the analysis of firm inefficiency. International Economic Review, $32(3): 715-723$.

[73] Robst, J. (2001). Cost efficiency in public higher education institutions. The Journal of Higher Education, 72:730-750.

[74] Ross, S. A. (1973). The economic theory of agency: The principaljs problem. American Economic Review, 63(2):134-139.

[75] Ruggiero, J. (1996). On the measurement of technical efficiency in the public sector. European Journal of Operational Research, 90:553-565.

[76] Shephard, R. W. (1953). Cost and Production Functions. Princeton University Press, Princeton, New Jersey.

[77] Shephard, R. W. (1970). Theory of Cost and Production Functions. Princeton University Press, Princeton, New Jersey.

[78] Simar, L., Lovell, K., and van den Eeckhaut P. (1994). Stochastic frontiers incorporating exogenous influences on efficiency. Discussion Paper No. 0317, Institut de Statistique, Universit'e Catholique de Louvain, Louvain-la-Neuve, Belgium.

[79] Slipersaeter, S. (2007). Variables for analysing higher education institutions in Europe. In Bonaccorsi, A. and Daraio, C., editors, Universities and stategic knowledge creation. Specialization and performance in Europe, pages 433-442. Edward Elgar. 
[80] Stevens, P. (2005). A stochastic frontier analysis of English and Welsh universities. Education Economics, 13:355-374.

[81] Teixeira, P., Amaral, A., Dill, D., and Jongbloed, B., editors (2004). Markets in higher education. Rhetoric or reality? Dordrecht: Kluwer Academic Publishers, volume 6 edition.

[82] Van der Meulen, B. (1998). Science policies as principal-agent games institutionalization and path dependency in the relation between government and science. Research Policy, 27:397-414.

[83] Van der Ploeg, F. and Veugelers, R. (2008). Towards evidence-based reform of European universities. CESifo Economic Studies, Vol. 54 (2):99-120.

[84] Winston, G. and Zimmerman, D. (2004). Peer effects in higher education. In Hoxby, C. M., editor, Colleges choices: The economics of where to go, when to go and how to pay for it, pages $395-424$. Chicago University Press.

[85] Wolszczak-Derlacz, J. and Parteka, A. (2011). Efficiency of european public higher education institutions: A two-stage multicountry approach. Scientometrics, 89:887917.

[86] Worthington, A. C. (2001). An empirical survey of frontier effciency measurement techniques in education. Education Economics, 9:245-268. 